\title{
High-Dose Phenobarbital-Induced Vitamin K Deficiency and Petechial Haemorrhage in a Young Female
}

\author{
Md Jahidul Hasan ${ }^{1, *}$, Dipesh Kumar Barua ${ }^{2}$, Ahmad Mursel Anam², and Raihan Rabbani² \\ ${ }^{1}$ Clinical Pharmacist (ICU \& Stewardship), Clinical Pharmacy Services, Department of Pharmacy, Square Hospitals Ltd., Dhaka, Bangladesh \\ ${ }^{2}$ Internal Medicine and ICU, Square Hospitals Ltd., Dhaka, Bangladesh
}

*Corresponding author: Md Jahidul Hasan, Clinical Pharmacist (ICU \& Stewardship), Clinical Pharmacy Services, Department of Pharmacy, Square Hospitals Ltd., Dhaka, Bangladesh, Tel: +8801911011167; E-mail: jahidul@squarehospital.com

Received: 13 Apr, 2020 | Accepted: 27 Apr, 2020 | Published: 05 May, 2020

Citation: Hasan MJ, Barua DK, Anam AM, Rabbani R (2020) High-Dose Phenobarbital-Induced Vitamin K Deficiency and Petechial Haemorrhage in a Young Female. J Clin Case Stu 5(2): dx.doi.org/10.16966/2471-4925.200

Copyright: (C) 2020 Hasan MJ, et al. This is an open-access article distributed under the terms of the Creative Commons Attribution License, which permits unrestricted use, distribution, and reproduction in any medium, provided the original author and source are credited.

\begin{abstract}
Phenobarbital is used in the management of seizure. Phenobarbital-induced adverse reactions are mostly common in infants and neonates, and related to its use during maternal age. Hepatic side effects are commonly associated with phenobarbitone. Here we present Vitamin $\mathrm{K}$ deficiency and petchial haemorrhage following the intake of high-dose Phenobarbital ( $2.4 \mathrm{~g})$ as a suicidal attempt in a young female. Initially, her coagulopathy was determined by assessing her high Prothrombin Time (PT) and Activated Partial Thromboplastin Time (aPTT), which were normalized by promptly using phytomenadione (Vitamin K1) intravenously within 6 days in Intensive Care Unit (ICU). Following the administration of phytomenadione injection, her symptoms of petechial haemorrhage were diminished on the fourth day in ICU. There was no significant change in her serum bilirubin level, and the initial raised serum aspartate aminotransferase and alanine aminotransferase returned to normal range within $24 \mathrm{~h}$. The patient found 2 sessions of hemodialysis in first two consecutive days in ICU, and discharged to home without any further complication.
\end{abstract}

Keywords: Phenobarbital; Vitamin K deficiency; Petchial haemorrhage; Phytomenadione; Prothrombin time; Activated partial thromboplastin time

\section{Introduction}

Barbituric acid, also known as barbiturate, was first recognized as a sleep inducing agent in 1903 [1] and one of its oldest family member, Phenobarbital, came under spotlight as an antiepileptic drug in 1912 [2]. Till 1977, phenobarbital was used worldwide in the management of seizures worldwide as contraindicated in mentally disoriented and hyperkinetic children $[3,4]$.

Drug-dependency was reported against Phenobarbital within the first year of its commercialization [5]. Because of the withdrawal syndromes (generally, at a dose of 4-6 times higher than the recommended dose) upon discontinuation of short-acting barbiturates, the Narcotics Expert Committee at the World Health Organization restricted the use of barbiturates without having medical prescription [1]. Since 1950s, phenobarbital-induced Adverse Drug Reactions (ADRs) such as, exfoliative dermatitis, Agranulocytosis, megaloblastic anemia, 'shoulder-hand' syndrome, osteomalacia, and Stevens-Johnson syndrome have been reported both in human and animal [6-13]. Vitamin K deficiency-associated bleeding disorder in neonates as a result of using phenobarbital during maternal age for epilepsy management has been reported in multiple studies [14-17]. In the natural blood coagulation process, Vitamin $\mathrm{K}$ plays a vital role in the activation of clotting cascades and an essential element of the body's hemostasis function [18,19]. Phenobarbital-associated Vitamin
$\mathrm{K}$ deficiency or coagulopathy in young adults is rare. Here, we found a case of high-dose phanobarbitone-induced Vitamin K deficiencyinduced coagulopathy and petechial haemorrhage in a young girl.

\section{Case Report}

A 20-year-old female was admitted to our Intensive Care Unit (ICU) through the Emergency Room (ER) with a history of ingesting 40 tablets of Phenobarbital $60 \mathrm{mg}$ (total phenobarbital consumption = $2.4 \mathrm{~g}$ ) about 10 hours ago as a suicidal attempt. During ER assessment, she was found with Glasgow Coma Scale (GCS) score of 4 (E-1, V-1 and M-2). Gastric lavage procedure was not performed in the patient in ER because of the long time gap. Her blood oxygen saturation $\left(\mathrm{SpO}_{2}\right)$ level was $84 \%$ at room air. Immediately, she was transferred to ICU, taken under mechanical ventilation support and her blood $\mathrm{SpO}_{2}$ level was maintained at $95 \%$ with a fraction of inspired oxygen $\left(\mathrm{FiO}_{2}\right)$ of $60 \%$. At the time of ICU admission, her pulse rate was 82 beats/minute, blood pressure was $100 / 55 \mathrm{~mm} \mathrm{Hg}$, body temperature was $99^{\circ} \mathrm{F}$; urine output was $60 \mathrm{~mL} / \mathrm{h}$; blood $\mathrm{pH}$ was 7.39 ; serum creatinine was $0.9 \mathrm{mg} / \mathrm{dL}$ (range: $0.8-1.4 \mathrm{mg} / \mathrm{dL}$ ); platelet count was $336 \mathrm{~K} / \mu \mathrm{L}$; serum albumin level was $3.2 \mathrm{~g} / \mathrm{dL}$ (range for adult: 3.5$5.0 \mathrm{mg} / \mathrm{dL}$ ); ammonia in serum was $54 \mu \mathrm{mol} / \mathrm{L}$; Serum Aspartate Aminotransferase (AST) level was $729 \mathrm{U} / \mathrm{L}$ (range: 15-46 U/L); Serum Alanine Aminotransferase (ALT) level was $118 \mathrm{U} / \mathrm{L}$ (range: 13-69 U/L); total serum bilirubin was $0.7 \mathrm{mg} / \mathrm{dL}$ (range: 0.2-1.2 mg/ 
dL); serum Lactic Acid Dehydrogenase (LDH) level was 11,539 U/L (range: 313-618 U/L); Serum Creatine Phosphokinase (CPK) level was $>16,000 \mathrm{U} / \mathrm{L}$ (range for female: 30-135 U/L), and blood beta Human Chorionic Gonadotropin (HCG) level was $<1.2 \mathrm{mIU} / \mathrm{mL}$ (range for non-pregnant female: $<5.0 \mathrm{mIU} / \mathrm{mL}$ ). Her serum barbiturates level was $>800 \mathrm{ng} / \mathrm{mL}$ (range: $<200 \mathrm{ng} / \mathrm{mL}$ ).

Petechial haemorrhage was detected all over her body mostly, on face (Figure 1) and upper trunk at the first ICU-day. Attempt to establish vascular access resulted in uncontrolled bleeding. Her Prothrombin Time (PT) was 50.6 second with an International Normalized Ratio (INR) of 5.38 and activated Partial Thromboplastin Time (aPTT) was 76.9 second (Figure 2). Immediately, a $10 \mathrm{mg}$ stat dose of phytomenadione (Vitamin K1) was injected intravenously and 6 units of fresh frozen plasma were administered intravenously. After about 6 hours, the bleeding from the vascular access site was stopped. Phytomenadione $5 \mathrm{mg}$ intravenously was prescribed as daily maintenance dose, and the PT and aPTT returned to normal range at her sixth ICU-day. The petechial haemorrhage was diminished on her fourth day in ICU and no other hemorrhage or bleeding sign was found. There was no evidence of reduction in the platelet count during her stay in ICU. For the phenobarbital toxicity management, 2 sessions of hemodialysis in two consecutive days (started on first ICU-day) was given to her. The first and second hemodialysis session was conducted over 8 hours and 4 hours, respectively and operated without heparin. After the second hemodialysis, patient's consciousness level improved with a GCS score of 12 (E-3, V-4 and M-5). Her initial raised serum ALT and AST levels returned to normal range within first $24 \mathrm{~h}$ in ICU. No elevation in serum bilirubin level was found. She was successfully weaned from mechanical ventilation on her fourth ICU-day. Her CPK level returned to normal at her fifth ICU-day. After resolving all the phenobarbital overdose-associated complications, she was discharged to home after staying 8 day in ICU.

\section{Discussion}

Phenobarbital is a century-old anticonvulsant drug widely used up to 1970 s worldwide $[1,2]$. Phenobarbital is a common therapeutic agent causing a number of potential adverse drug events reported worldwide including bleeding disorder, systemic reactions and mil-to-severe skin reactions [6-13]. Blood coagulopathy is a well recognized adverse event associated with phenobarbital mostly reported in neonates

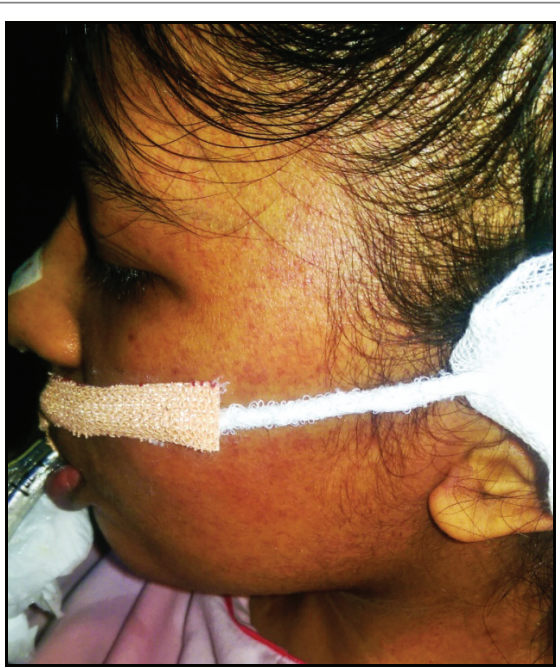

Figure 1: Petechial haemorrhage due to high-dose Phenobarbital.

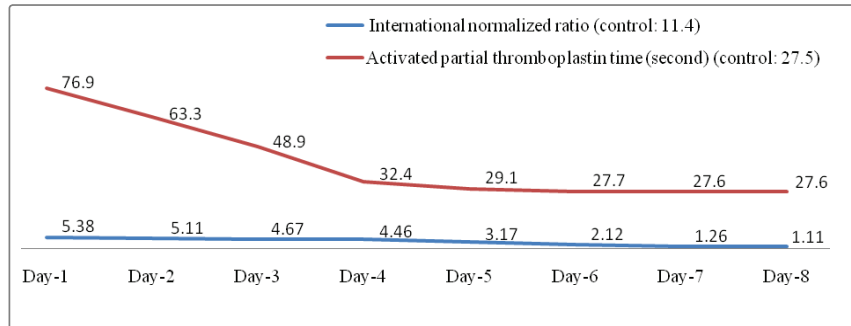

Figure 2: Blood coagulation disorder due to high-dose Phenobarbital.

[15-17]. Data on young or adult people related to recommended dose or high-dose of phenobarbital-associated bleeding disorder is under-reported $[1,3]$. In our case, the young adult female developed Vitamin $\mathrm{K}$ deficiency resulting in high PT and aPTT, and petechial haemorrhage with high-dose of oral phenobarbital (2.4 g). After eight days treatment in ICU, the patient was recovered well.

Drug-induced Vitamin $\mathrm{K}$ deficiency is a known phenomenon $[18,19]$, which is determined either by the elevation of PT and aPTT through lab test or by experiencing acute bleeding incidence $[16,20,21]$. Vitamin K (especially Vitamin K1) acts as a coenzyme for Vitamin K-dependent carboxylase (catalyst of $\gamma$-carboxylation glutamic pathway) essential for the synthesis of clotting factors II (prothrombin), VII, IX and X necessary for hemostasis [20,21]. Protrombin participates directly in blood coagulation process. Other clotting factors are enabled through the $\gamma$-carboxylation process by binding with calcium, come in contact with phospholipid membrane and form clot [21]. In addition, Vitamin $\mathrm{K}$ reductase reverts inactive Vitamin K1 2,3-epoxide back to Vitamin $\mathrm{K}$ hydroquinone which accomplish the remaining $\gamma$-carboxylation reactions and coagulation takes place properly [20,21]. Thus, increased rate of Vitamin $\mathrm{K}$ metabolism resulting in Vitamin $\mathrm{K}$ deficiency which cause improper blood coagulation cascade leading to bleeding risk [21]. A study found that high-dose of phenobarbital increases the overall functions of hepatic mixed-function oxidase system, but this does not significantly interfere in the metabolic pathway of Vitamin $\mathrm{K}$ [20]. In rats and rabbits, high daily dose of phenobarbital resulted in increased metabolism rate of Vitamin $\mathrm{K}$ [22]. The actual contributing factor(s) behind this enhanced metabolism rate is still not clear. To date, alteration in associated hepatic enzymes functions, increased blood flow in liver, and alteration in Vitamin-K-lipoprotein binding are thought to be the major factors $[14,20,22]$. In this case, the patient developed Vitamin K deficiency with elevated liver enzymes which was confirmed by the elevated PT, aPTT and active bleeding from the vascular access site. Phytomenadione supplements ultimately reverted Vitamin $\mathrm{K}$ to its normal level which enabled normal blood coagulation cascade.

Petechiae are tiny, circular, non-raised patches developed on the skin which are typically called petechial haemorrhage when petechiae are resulted because of bleeding or leaking blood under the skin [23]. Vitamin K deficiency-induced petechial haemorrhage has been reported in infants [24], but evidence in adult is uncommon. In this case, high-dose phenobarbital caused Vitamin $\mathrm{K}$ deficiency in the patient resulting in petechial haemorrhage through capillary bleeding beneath the skin. When the Vitamin K level was restored, PT and aPTT returned to normal range, and then the symptoms of petechial haemorrhage were resolved completely. Lack of biochemical tests for the confirmation of phenobarbital-induced Vitamin K deficiency, and shortage of relevant data are the major limitations of this study. 


\section{Conclusion}

Phenobarbital-induced Vitamin K deficiency-associated bleeding disorder is common in infants and neonates related to maternal intake. However, in young or adult, bleeding disorder associated with phenobarbital is less evidenced. Here, we found a young female developed acute Vitamin $\mathrm{K}$ deficiency and petechial haemorrhage with high-dose phenobarbital intake.

\section{Acknowledgments}

The authors are very grateful to the Square hospitals Ltd. and the patient for the permission of this study.

\section{Financial Disclosure/Grant Support}

None to declare.

\section{Conflict of Interest}

The authors declare they have no competing interests.

\section{Informed Consent}

The signed informed consent was obtained from the patient before conducting the study.

\section{Author Contributions}

Md Jahidul Hasan took the patient consent for the study, and was involved in patient care, data collection, literature search, background research, manuscript writing and numerous rounds of editing. Dipesh Kumar Barua was involved in patient care and numerous rounds of editing. Ahmad Mursel Anam was involved in patient care and numerous rounds of editing. Raihan Rabbani was involved in patient care and numerous rounds of editing.

\section{Data Availability}

Not applicable.

\section{References}

1. Yasiry Z, Shorvon SD (2012) How phenobarbital revolutionized epilepsy therapy: the story of phenobarbital therapy in epilepsy in the last 100 years. Epilepsia 53: 26-39.

2. López-Muñoz F, Ucha-Udabe R, Alamo C (2005) The history of barbiturates a century after their clinical introduction. Neuropsychiatr Dis Treat 1: 329-343.

3. Haward F (1928) Report of the medical officer. The National Society for Epileptics. Thirty-fifth Annual Report 24.

4. Goldenberg MM (2010) Overview of drugs used for epilepsy and seizures: etiology, diagnosis, and treatment. P T 35: 392-415.

5. Glatt MM (1962) The abuse of barbiturates in the United Kingdom. United Nations Office on Drugs and Crime [UNODC]. Bull Narc 2: 19-38.

6. Sexton DL, Pike GM, Nielson A (1941) Exfoliative dermatitis and death due to Phenobarbital. JAMA 116: 700-701.
7. Sneddon IB, Lishman AW (1952) Severe and fatal phenobarbitone eruprtions. Br Med J 1: 1276-1278.

8. Bruck E (1947) Agranulocytosis in Childhood: Report of a case with serial bone marrow studies. Am J Dis Child 73: 186-194.

9. Hawkings CF, Meynell MJ (1958) Macrocytosis and macrocytic anaemia caused by anticonvulsant drugs. Q J Med 27: 45-63.

10. Chanarin I, Laidlaw J, Loughridge LW, Mollin DL (1960) Megaloblastic anaemia due to phenobarbitone. Br Med J 1: 1099-1102.

11. Van Der Korst JK, Colenbrander H, Cats A (1960) Phenobarbital and the shoulder-hand syndrome. Ann Rheum Dis 25: 553-555.

12. Kruse $R$ (1968) Osteopathies in antiepileptic long-term therapy (preliminary report). Monatsschr Kinderheilkd 116: 378-381.

13. Cornelis I, Vandenabeele S, Dunon D, Van Ham L (2016) Presumed phenobarbital-induced Stevens Johnson syndrome in a 4-year-old female Great Dane. Vet Q 36: 242-246.

14. Rezvani M, Koren G (2006) Does Vitamin K prophylaxis prevent bleeding in neonates exposed to enzyme-inducing antiepileptic drugs in utero? Can Fam Physician 52: 721-722.

15. Mountain KR, Hirsh J, Gallus AS (1970) Neonatal coagulation defect due to anticonvulsant drug treatment in pregnancy. Lancet 295 : 265-268.

16. Van Creveld S (1958) New aspects of hemorrhagic disease of the newborn. Arch Fr Pediatr 15: 721-735.

17. Shankaran S, Cepeda EE, llagan N, Mariona F, Hassan M, et al. (1986) Antenatal phenobarbital for the prevention of neonatal intracerebral hemorrhage. Am J Obstet Gynecol 154: 53-57.

18. Almazroo OA, Miah MK, Venkataramanan R (2017) Drug Metabolism in the Liver. Clin Liver Dis 21: 1-20.

19. Vermeer C (2012) Vitamin K: the effect on health beyond coagulation - an overview. Food Nutr Res 56.

20. Park BK, Wilson AC, Kaatz G, Ohnhaus EE (1984) Enzyme induction by phenobarbitone and Vitamin K1 disposition in man. Br J Clin Pharmacol 18: 94-97.

21. Institute of Medicine (US) Panel on Micronutrients (2001) Dietary reference intakes for Vitamin A, Vitamin K, arsenic, boron, chromium, copper, iodine, iron, manganese, molybdenum, nickel, silicon, vanadium, and zinc. Washington (DC): National Academies Press (US).

22. Wilson AC, Park BK (1983) Quantitative analysis of pharmacological levels of Vitamin K1 and Vitamin K1 2,3-epoxide in rabbit plasma by high-performance liquid chromatography. J Chromatogr 277: 292299.

23. Jaffe FA (1994) Petechial hemorrhages. A review of pathogenesis. Am J Forensic Med Pathol 15: 203-207.

24. Sunil G (1997) Vitamin K deficiency bleeding in infancy. J Trop Pediatrics 43: 122 . 